\title{
LOS OJOS Y EL ALCOHOL
}

\section{THE EYES AND ALCOHOL}

\author{
RODRÍGUEZ FD ${ }^{1}$
}

Los ojos conectan el mundo exterior con el cerebro y sirven de soporte para la elaboración de un cosmos visual interno compuesto tanto de elementos externos como internos, aportados por la experiencia individual y colectiva, y modulado por variadas influencias. Los ojos dirigen a nuestro cerebro estímulos diversos del mobiliario circundante. El alcohol, por ejemplo, es una oferta asequible, por lo general atractiva, en ocasiones esclavizante, de la geografía que frecuentamos. Los ojos sirven al cerebro para la entrada de estímulos que alimentan y refuerzan los circuitos de la búsqueda y disfrute del placer.

En nuestro entorno, conocemos el alcohol en sus variadas manufacturas fermentadas y destiladas. Celebramos y lamentamos con alcohol en forma de vino, cerveza, o destilados. Sin embargo, a pesar de esta familiaridad estamos aún lejos de comprender cómo actúa en nuestro organismo. Por ejemplo, no sabemos por qué reduce la ansiedad, cómo actúa sobre la timidez de un individuo, de qué forma convierte el campo visual en una estampa desdibujada y móvil, cómo afecta los mecanismos inhibitorios, intencionales y automáticos, componentes de la atención visual o los procesos metabólicos subyacentes en el mecanismo molecular de la visión, el mantenimiento de la presión intraocular o la nutrición de las estructuras oculares. Tampoco entendemos si el alcohol ejerce efectos específicos sobre la arquitectura funcional del ojo o, por el contrario, su acción es difusa e imprecisa.

El alcohol etílico es una molécula de estructura sencilla (dos átomos de carbono, 6 de hidrógeno y uno de oxígeno). Es transparente y tiene consistencia líquida a temperatura ambiente. Su densidad $(0,8 \mathrm{~g} / \mathrm{mL})$ es menor que la del agua $(1 \mathrm{~g} / \mathrm{mL})$. Cuando es ingerido o inyectado llega, por medio del torrente circulatorio, a todos los rincones del organismo (aunque tiene más dificultad para alcanzar los tejidos grasos). Cruza las membranas plasmáticas de las células, haciéndose hueco entre sus lípidos y proteínas constituyentes y se pone en contacto con todo el aparato molecular que encierran: sistemas metabólicos, transporte vesicular, maquinaria de síntesis y reparto de las proteínas, señalización química intracelular o tráfico de macromoléculas entre el núcleo y el citoplasma, entre otros.

\section{DIANAS MOLECULARES DEL ALCOHOL}

La morfina o los cannabinoides son sustancias exógenas (como el etanol) que se unen a receptores específicos que son reconocidos, a su vez, por los opioides y los cannabinoides endógenos, respectivamente. Sin embargo, no se conoce una diana molecular específica para el etanol. Su acción ha sido considerada inespecífica y fundamentalmente relacionada con su capacidad para alterar la composición química de las membranas celulares y, consecuentemente, sus funciones de transporte y reconocimiento. En los últimos años, se han descrito dianas proteicas que son más sensibles a su presencia. Algunos ejemplos son los receptores tipo A para el GABA (ácido gamma-amino butírico), el receptor tipo NMDA (Nmetil-D -aspartato) para el glutamato, el receptor de la glicina, algunos tipos de adenilato ciclasa o conductos de potasio (1). Las dianas mencionadas se ven afectadas a concentraciones de etanol situadas en el rango milimolar (los neurotransmisores, las hormonas y muchos fármacos actúan, por lo general, en el rango femto y nanomolar). A pesar de que no se haya descrito una diana específica, es interesante profundizar en el conocimiento de las proteínas que exhiben una mayor sensibilidad a la presencia del alcohol. Estos análisis nos permitirán evaluar con mayor rigor el daño alcohólico.

\footnotetext{
1 Profesor Titular de Bioquímica. Departamento de Bioquímica y Biología Molecular. Universidad de Salamanca. Salamanca. España. E-mail: lario@usal.es
} 


\section{EMISARIOS DEL ALCOHOL}

A la hora de estudiar la acción del alcohol sobre una célula, un órgano o un sistema, no debe descartarse la posibilidad de que intervenga no sólo de forma directa sino también por medio de algunos compuestos derivados de su metabolismo. Uno de ellos es el acetaldehído (procedente de la acción oxidante de la enzima alcohol deshidrogenasa o ADH). El acetaldehído es tóxico pero su vida media es muy corta ya que el organismo se encarga, por medio de la enzima aldehído deshidrogenasa, de neutralizarlo a un compuesto inocuo: el acetato (vinagre). A su vez, este es reutilizado rápidamente en el ciclo metabólico del citrato. Una molécula derivada del metabolismo no oxidativo del alcohol es el fosfatidiletanol, un fosfolípido aniónico que se inserta en las membranas celulares a expensas de la reducción del fosfolípido natural del cual se deriva, el ácido fosfatídico, por la actividad de la fosfolipasa D (2). El etanol puede también reaccionar con los ácidos grasos para dar lugar a ésteres de ácidos grasos y etanol o ésteres etílicos de ácidos grasos (EEAG). La incorporación del etanol a la estructura del ácido graso da lugar a una nueva molécula que es bastante estable. Al incorporarse a las membranas de las células, el fosfatidiletanol y los EEAG pueden provocar cambios en su arquitectura y, como consecuencia, dañar la función de muchas proteínas que se insertan en las mismas (receptores, conductos para iones, transportadores...) Su estabilidad química hace que permanezcan durante tiempos prolongados en las células. El hallazgo de estos compuestos ha facilitado su empleo como biomarcadores del consumo alcohólico.

\section{EFECTOS TERATOGÉNICOS DEL ALCOHOL EN EL GLOBO OCULAR}

El impacto del alcohol sobre los procesos de desarrollo ha sido estudiado en el contexto genérico de los denominados desórdenes fetales provocados por el alcohol o FASD (Fetal Alcohol Spectrum Disorders). El FAS, síndrome fetal alcohólico, es la forma más severa de FASD. El alcohol que la madre bebe durante el embarazo provoca en el embrión y el feto alteraciones cráneo-faciales que comienzan a cristalizar fundamentalmente en los estadios de gastrulación e incluyen, entre otras, microcefalia, retraso mental, acortamiento de la fisura palpebral y defectos oculares variables (microoftalmia, coloboma uveal, microfaquia, tortuosidad en los vasos de la retina...). El alcance y severidad del daño se relaciona con la cantidad de alcohol bebida y el patrón de ingesta. Algunos estudios apuntan que el etanol puede actuar como un inhibidor competitivo del metabolismo del ácido retinoico (RA) $(3,4)$. El RA tiene un papel plurifacético en la embriogénesis y organogénesis de vertebrados (5) y la reducción de sus niveles, como consecuencia de la presencia del etanol, puede dar lugar a las alteraciones mencionadas. Pero el mecanismo de acción preciso no es conocido. No se descartan otros como la inducción de apoptosis, modificaciones de la adhesión celular, acumulación de radicales libres... (4).

Con el fin de bloquear el efecto teratogénico del alcohol se han propuesto terapias basadas en experimentos llevados a cabo en animales. Por ejemplo, se ha probado en ratones que el factor neurotrófico ADNF (Activity-Dependent Neurotrophic Factor), en su forma isomérica D, administrado por vía oral, previene los efectos oculares inducidos por el alcohol durante la embriogénesis (6). Aun cuando estas terapias ofrecen resultados prometedores es dudoso que la farmacoterapia sea la mejor solución. Los efectos del alcoholismo pueden prevenirse, tanto en el adulto como en el feto, evitando la ingesta alcohólica. Es importante resaltar que el feto no tiene ninguna capacidad de decisión al respecto. En el caso particular de los FASD, el estudio y diseño de medidas preventivas es de gran importancia.

\section{BIBLIOGRAFÍA}

1. Harris RA, Trudell JR, Mihic SJ. Ethanol's molecular targets. Sci Signal 2008; 1: re7.

2. Gustavsson L, Alling C. Formation of phosphatidylethanol in rat brain by phospholipase D. Biochem Biophys Res Commun 1987; 142: 958-963.

3. Duester G. A hypothetical mechanism for fetal alcohol syndrome involving ethanol inhibition of retinoic acid synthesis at the alcohol dehydrogenase step. Alcohol Clin Exp Res 1991; 15: 568-572.

4. Yelin R, Schyr RB, Kot H, Zins S, Frumkin A, Pillemer G, et al. Ethanol exposure affects gene expression in embryonic organizer and reduces retinoic acid levels. Dev Biol 2005; 279: 193-204.

5. Mark M, Ghyselinck NB, Chambon P. Function of retinoid nuclear receptors: lessons from genetic and pharmacological dissections of the retinoic acid signaling pathway during mouse embryogenesis. Annu Rev Pharmacol Toxicol 2006; 46: 451-480.

6. Parnell SE, Chen SY, Charness ME, Hodge CW, Dehart $D B$, Sulik KK. Concurrent dietary administration of $D$ SAL and ethanol diminishes ethanol's teratogenesis. Alcohol Clin Exp Res 2007; 31: 2059-2064. 